\title{
PERSPECTIVAS DE ESTUDOS COMPARADOS A PARTIR DA APLICAÇÃO DA ESCALA LIKERT DE 4 PONTOS: UM ESTUDO METODOLÓGICO DA PESQUISA TALIS
}

\author{
Rose Meri TROJAN ${ }^{1}$ \\ Robson SIPRAKI ${ }^{2}$
}

RESUMO: Este estudo analisa a utilização da Escala Likert na pesquisa Teaching and Learning International Survey (TALIS). O tema justifica-se pelo uso recorrente da estatística nas pesquisas educacionais, especialmente, aquelas que permitem estudos comparados internacionais. O objetivo é avaliar análises apresentadas no relatório TALIS (OCDE, 2009) e verificar as perspectivas do uso da Escala Likert em estudos que utilizam os resultados desta pesquisa. Metodologicamente, partiu-se dos fundamentos estatísticos e procedimentos técnicos relacionados à escala, com base em Reis (1997), Garland (1991) e Oliveira (2001), entre outros, para examinar algumas questões aplicadas aos professores que utilizam a escala Likert de quatro pontos. No caso, Garland (1991) adverte que esta opção pode reforçar uma tendência e compelir os respondentes a marcarem a opção considerada mais adequada. Entre os resultados foram identificados problemas na formulação das questões aplicadas e nas análises presentes no relatório, que prejudicam a avaliação dos temas investigados na pesquisa TALIS.

PALAVRAS-CHAVE: Políticas educacionais. TALIS. Estatística.

\section{Introdução}

Este estudo analisa a utilização da Escala Likert na pesquisa Teaching and Learning International Survey (TALIS), da Organização de Cooperação e Desenvolvimento Econômico (OCDE, 2009), tomando como referência os questionários aplicados aos professores. $\mathrm{O}$ tema se justifica pela expressiva importância conferida à estatística em pesquisas educacionais de larga escala, especialmente aquelas que permitem estudos comparativos internacionais, realizadas por organismos multilaterais, com a finalidade de avaliar a qualidade da educação e as políticas educacionais. Assim, o objetivo é avaliar análises apresentadas no relatório TALIS

\footnotetext{
${ }^{1}$ Doutora em Educação. UFPR - Universidade Federal do Paraná. Professora Associada de Graduação e Pós-graduação. UFPR - Universidade Federal do Paraná. Curitiba - PR - Brasil. 80060-150 rosetrojan@uol.com.br.

${ }^{2}$ Mestre em Educação. UFPR - Universidade Federal do Paraná. Consultor Estatístico e Professor da Rede Estadual de ensino do Paraná. Curitiba - PR - Brasil. 80060-150 - robsonsipraki@ gmail.com.
} 
(OCDE, 2009) e verificar as perspectivas do uso da Escala Likert em estudos que utilizam os resultados desta pesquisa.

De modo geral, os dados baseados em métodos estatísticos não são discutidos ou postos em dúvida. Todavia, os métodos estatísticos escolhidos têm limites e apresentam margem de erro. A estatística é apenas um instrumento a serviço da pesquisa e é um equívoco pensar que esta é sempre capaz de fornecer resultados conclusivos através dos resultados obtidos. De modo geral, os relatórios das pesquisas realizadas por organizações internacionais e órgãos oficiais de governo apresentam somente uma estatística descritiva, ou seja, apenas descrevem quantitativamente os acontecimentos, sem realizar uma interpretação dos dados, que exigiria a aplicação da estatística inferencial.

Além disso, é necessário ressaltar que a escolha do método e o modo como é utilizado nas pesquisas têm impacto significativo sobre os dados obtidos e sobre as possibilidades de utilizar os resultados como meio de avaliar políticas e realizar estudos comparativos. Para verificar as perspectivas de utilização da Escala Likert em pesquisas educacionais, toma-se como objeto a pesquisa TALIS (OCDE, 2009), a partir do estudo do relatório publicado em 2009 e algumas questões dos questionários aplicados aos professores e diretores.

Metodologicamente, o ponto de partida é a retomada dos fundamentos da Estatística e procedimentos técnicos relacionados à Escala Likert, com base em Reis (1997), Garland (1991) e Oliveira (2001), entre outros, para subsidiar a análise. Além disso, o estudo é fundamentado em pesquisadores do campo das políticas educacionais, tais como Freitas (2011) e Saviani (2005) e da educação comparada, como Ferrer (2002) e Beech (2012).

Para estudar a aplicação dessa escala na pesquisa TALIS (OCDE, 2009), será descrita a base teórica, incluindo origem, objetivos, escopo, procedimentos técnicos, vantagens e desvantagens da sua utilização. A intenção é ponderar sobre as perspectivas de análise possíveis em estudos comparados, decorrentes da pesquisa em foco. Assim sendo, foram selecionadas as questões do questionário do professor e do diretor da pesquisa TALIS (OCDE, 2009) que utilizam a de quatro pontos, para analisar a aplicação da escala e sua adequação para medir o tema proposto e, finalmente, verificar os impactos dessa escolha nas possibilidades de resposta dos professores e na interpretação dos dados. 


\section{O uso da estatística na pesquisa}

A estatística oferece ferramentas importantes para trabalhar com dados empíricos e subsidiar tomadas de decisão. Assim, a aplicação da estatística na pesquisa em geral e na educação, em particular, tem se tornado cada vez mais evidente. Abrange um conjunto de métodos e técnicas que possibilitam provar ou refutar hipóteses em um dado estudo (MATTAR, 2001). Nesse contexto, torna-se imperativo o conhecimento sobre Estatística para planejar, coletar, organizar e interpretar corretamente os dados necessários para realização de uma pesquisa.

A base para qualquer análise de dados consiste em estabelecer o tipo de medida que deve ser utilizado, porque é através desta que é escolhido o método de análise mais apropriado. Assim como existem características ou atributos que podem ser medidos, em contrapartida existem os que não podem, sendo necessário criar os instrumentos mais apropriados. Reis (1997) afirma que existem duas qualidades básicas para que um indicador represente o conceito teórico para o qual foi criado e que se propõe a medir que são: validade e fiabilidade. Sobre essas qualidades, a autora esclarece que:

\footnotetext{
Um instrumento de medida de determinado conceito abstrato é válido se conseguir efetivamente medir aquilo para que foi desenvolvido e é fiável se medir os mesmos resultados em experiências repetidas em idênticas condições. Por exemplo, um teste feito para aferir os conhecimentos absorvidos por um grupo de alunos ao longo de um ano eletivo é válido se conseguir efetivamente distinguir os alunos com maior aprendizagem dos que nada conseguiram absorver ao longo do ano. (REIS, 1997 p.29).
}

Para conhecer as Escalas de Medida, é importante compreender primeiro a distinção entre mensuração e medida. Mensuração é o processo do qual resulta a medida, ou seja, atribuir certas grandezas (valores) aos dados obtidos, e medida é o valor (número) resultante da mensuração, portanto, medir é atribuir um número e a esse número atribuir-se um nível ou escala, que é utilizada para a análise estatística (CRESPO, 2002).

As escalas de medida são utilizadas para a elaboração dos instrumentos de coleta de dados. Cada escala de medida possui seu próprio conjunto de pressupostos, referentes à correspondência com números e à realização das várias operações matemáticas com esses números. 
Entre os vários tipos de escala que podem ser utilizados, a estatística propõe: nominal, para identificação e definição única de números; ordinal, para ordenação numérica; intervalar, para comparação de intervalos; e de razão, para comparação de medidas absolutas e de proporções (MATTAR, 1993). Assim sendo, para cada uma delas, existem possibilidades e limitações. Nesse caso, a escolha está condicionada a estes fatores, indicados por Oliveira (2001, p.3):

[...] os pesquisadores devem estar atentos para identificar quais as características do constructo estão sendo medidas e quais são as propriedades do sistema numérico que se referem ao constructo para, a partir daí, escolher a técnica que melhor se adapta ao problema de pesquisa. Em suma, é possível dizer que a escolha de um formato apropriado para a pesquisa deve levar em consideração a natureza da variável a ser medida, a habilidade dos respondentes de fazer julgamentos e os tipos de análise a serem desenvolvidos.

Em uma escala nominal, os números servem apenas para categorizar dados sobre pessoas, objetos, etc. Ou seja, é um tipo de escala menos sofisticado, na qual os números servem como legendas para identificar diferentes categorias. Este rótulo pode ser numérico, porém esses números não são utilizados para contagem do número de respostas, mas para identificar cada categoria. Exemplo: sexo (feminino [1] e masculino [2]), cidades ([1], [2], [3], [4]...), graus de instrução, estado civil, cor dos olhos, etc. (OLIVEIRA, 2001).

As escalas ordinais se distribuem a partir de certa ordem, que pode ser crescente ou decrescente, permitindo estabelecer diferenciações, ou seja, podem nomear, identificar e categorizar objetos, pessoas ou fatos. As medidas de tendência central que podem ser utilizadas são a moda e a mediana, e as medidas de dispersão, quartis e percentis. É o que se obtém quando se pede ao sujeito pesquisado que ordene um conjunto de atributos (REIS, 1997). Por exemplo: Quanto tempo você gasta por semana para planejar suas aulas? 1. Menos de 2 horas; 2. De 2 a 4 horas; 3. De 4 a 8 horas; 4. Mais de 8 horas. Também se utiliza para estabelecer uma classificação: do $1^{\circ}$ ao último lugar, nível social, nível salarial e escalas usadas nas medidas de opinião, como por exemplo, a Escala Likert.

As variáveis definidas numa escala intervalar configuram uma forma quantitativa de registar um fenômeno, medindo a sua intensidade específica, ou seja, “[...] além da classificação e ordenação dos seus valores, permitem o cálculo de 
distâncias ou diferenças entre observações.” (REIS, 1997, p.31). Portanto, este tipo de escala possui uma distância entre si com valores reais em relação à determinada característica. Morais (2005, p.6) ressalta que nessa escala “[...] a diferenciação dos indivíduos ou das observações assume um valor quantitativo constante", e que esses valores “[...] envolvem classificação, grandeza e unidades de tamanhos idênticos". Um exemplo clássico são as escalas de temperatura, nas quais não se pode assumir um ponto zero como ausência de temperatura, ou dizer que a temperatura $X$ é o dobro da temperatura Y (MORAIS, 2005). Essas escalas são mais poderosas do que as escalas ordinais, porque as diferenças entre valores das escalas de intervalo podem ser interpretadas significativamente, utilizando as medidas de tendência central (média, mediana e moda) e as medidas de dispersão (desvio padrão, coeficiente de variação, amplitude total, quartis e percentis). Em pesquisas de opinião, essa escala também pode ser utilizada na Escala Likert, desde que seja atribuído um valor para cada variável.

Finalmente, as escalas de razão possuem, além das mesmas propriedades das escalas de intervalo, a vantagem de medir a magnitude absoluta e o quanto as variáveis (pessoas ou objetos) estão distantes entre si, em relação à determinada característica (OLIVEIRA, 2001).

Assim sendo, quando se têm valores de certa característica, é fácil constatar que os dados normalmente não se distribuem uniformemente, havendo certo agrupamento. Pode-se, portanto, estudar os valores numéricos que determinam a distribuição dos dados, procurando o ponto onde está a maior concentração de valores individuais. De um modo geral, um conjunto de dados pode ocupar uma posição específica dentro de uma distribuição. Essas medidas que "posicionam" o dado (ou o grupo de dados) dentro de uma distribuição são chamadas de medidas de tendência central, que englobam média, mediana e a moda - que representam elementos pelos seus valores médios, em torno dos quais se concentram os dados - e as medidas de dispersão, que envolvem o desvio padrão e o coeficiente de variação (REIS, 2008). São exemplos de escalas de razão: a idade, salário, preço, volume de vendas, distâncias (Tabela1).

\section{Tabela 1 - Idade dos alunos da Turma A}

$$
\text { ALUNOS IDADE }
$$

\begin{tabular}{ll}
\hline 1 & 11 \\
2 & 10 \\
3 & 11
\end{tabular}




$\begin{array}{cc}4 & 12 \\ 5 & 15 \\ 6 & 09 \\ \text { Média } & 11,3\end{array}$

Fonte: Elaboração própria.

Contudo, antes de analisar as características e possibilidades de aplicação da Escala Likert, é essencial esclarecer ainda que a opção por uma escala ou outra se encontra no fato de que alguns tipos permitem certas operações matemáticas e outras não (REIS, 1997). Portanto, é necessário conhecer as possibilidades de cada uma das escalas. Segundo Oliveira (2001, p.3):

[...] os pesquisadores devem estar atentos para identificar quais as características do constructo estão sendo medidas e quais são as propriedades do sistema numérico que se referem ao constructo para, a partir daí, escolher a técnica que melhor se adapta ao problema de pesquisa. Em suma, é possível dizer que a escolha de um formato apropriado para a pesquisa deve levar em consideração a natureza da variável a ser medida, a habilidade dos respondentes de fazer julgamentos e os tipos de análise a serem desenvolvidos.

\section{A Escala Likert}

A escala Likert surgiu de um relatório publicado em 1932, cujo autor - educador e psicólogo americano - Rensis Likert, explica o método que aborda um tipo de escala de resposta psicométrica. É a mais utilizada em questionários e pesquisas de opinião, onde os entrevistados respondem perguntas baseadas em escalas, através de níveis de discordância ou concordância (LIMA et al., 2012).

Esta escala pode ser ordinal ou intervalar. Quando se aplica a escala ordinal só se podem usar dois tipos de medida de tendência central: a mediana e a moda, utilizando as estatísticas não paramétricas; no caso da intervalar, além das duas medidas citadas, pode-se utilizar a média, os desvios e a estatística paramétrica. Essas regras também devem ser estudadas para avaliar a validade do processo (MORAIS, 2005).

As escalas de Likert, ou escalas somatórias, dizem respeito a uma série de afirmações relacionadas com o objeto pesquisado, utilizando para isso mais de um tipo de escala, entre as descritas anteriormente. Ou seja, “[...] os respondentes não apenas respondem se concordam ou não com as afirmações, mas também informam qual seu grau de concordância ou discordância.” (OLIVEIRA, 2001, p.19). Desse modo: 
Em geral são utilizadas na escala de Likert quatro ou cinco categorias ordinais. Como ilustração pode ser citada, para quatro categorias, 0 nada importante, 1 - pouco importante, 2 - importante e 3 - muito importante, e para cinco categorias, 0 - muito baixo, 1 - baixo, 2 médio, 3 - alto e 4 - muito alto. (ALEXANDRE et al., 2003, p.1).

Neste sentido, atribui-se um número para cada resposta, com a finalidade de medir a atitude do respondente em relação a cada afirmação. Segundo Oliveira (2001, p.19): “A somatória das pontuações obtidas para cada afirmação é dada pela pontuação total da atitude de cada respondente". Podem-se utilizar escalas que variam "[...] de quatro a onze categorias, mas as escalas de quatro e de cinco são as mais populares" (ALEXANDRE et al., 2003, p.3).

Inicialmente, são coletadas as várias informações sobre determinadas afirmações, em relação às quais são oferecidas opções com graus de intensidade ou importância. Para cada ponderação é feito um score ou contagem final computando as respostas na escala escolhida. Por exemplo, em uma escala que varia de 5 a 1 , a avaliação das frases pode ser feita de acordo com as seguintes opções: concordo totalmente, concordo parcialmente, neutra, discordo parcialmente e concordo totalmente. Para cada grau de concordância ou discordância é atribuído um número para indicar a direção da atitude do respondente (OLIVEIRA, 2001, p.19). Segundo Mattar (1996, p.97), “[...] o conjunto de números utilizados não faz diferença em função das conclusões a que se quer chegar, o importante é que se atribua corretamente os números às respostas de afirmações positivas e negativas". Porém, deve-se ter cuidado quando a pesquisa envolve a opinião do entrevistado, que decorre da sua percepção subjetiva, ou seja:

Uma das grandes preocupações em qualquer pesquisa, em particular, aquelas onde o elemento humano é a unidade a ser pesquisada ou o fornecedor das informações investigadas com base na sua percepção, é o fiel registro dessas informações, isto é, o que se deseja registrar é a opinião do entrevistado que retrate a realidade do fenômeno estudado (ALEXANDRE et al., 2003, p.2).

Assim, a discussão em torno da escala Likert ocorre quando se define a mensuração dos dados. Poynter (2010), explica que os dados podem ser tratados com a determinação dos dados de intervalo (por exemplo, 1, 2, 3) ou produzidos como 
ordinais $\left(1^{\circ}, 2^{\circ}\right.$ e $\left.3^{\circ}\right)$. Para o tratamento de dados a partir de um item de tipo Likert, se a escala é de intervalo, o pesquisador precisa saber se a diferença entre "concordo" e "discordo" é exatamente duas vezes maior que a diferença entre "Discordo totalmente" e "Discordo". Se a escala é ordinal, a diferença entre "Discordo totalmente" e "Discordo" é numericamente a mesma que a diferença entre "Concordo" e "Não concordo, nem discordo", ou seja, para "não aceito" (discordo totalmente, discordo) e "aceito" (concordo totalmente e concordo). Se os dados forem ordinais, podem-se identificar esses dados através da mediana, da moda ou da porcentagem, porém não se pode calcular o desvio padrão.

Uma vantagem da escala de Likert é a possibilidade de identificar a direção da atitude do respondente em relação a cada afirmação, sendo ela positiva ou negativa. Poynter (2010) argumenta que, quando se usa dados de escala de intervalo na Likert também existe a possibilidade de usar a média e o desvio padrão, e também usar as formas regulares de técnicas como a análise fatorial e a de regressão. Brandalise (2005, p.4) explica que:

\begin{abstract}
As principais vantagens das escalas Likert, são a simplicidade de construção; o uso de afirmações que não estão explicitamente ligadas à atitude estudada, permitindo a inclusão de qualquer item que se verifique, empiricamente, ser coerente com o resultado final; e ainda, a amplitude de respostas permitidas apresenta informação mais precisa da opinião do respondente em relação a cada afirmação. Como desvantagem, por ser uma escala essencialmente ordinal, não permite dizer quanto um respondente é mais favorável a outro, nem mede o quanto de mudança ocorre na atitude após expor os respondentes a determinados eventos.
\end{abstract}

Para Chisnall (1973, p.174) uma desvantagem, é que "[...] a escala de Likert não produz uma escala de intervalos, ela não é adequada para concluir sobre o significado das distâncias entre posição das escalas", o que só pode ser obtido com a escala de razão. Deste ponto de vista, Ockert (2005) explica que os dados procedentes das escalas Likert permitem estabelecer relação de equivalência e de comparação. Portanto, tais dados admitem apenas a ordenação da atitude de concordância dos indivíduos com relação à determinada afirmação, mas não apresenta condições para dizer o quanto o indivíduo concorda mais do que outro.

Neste sentido, pode-se afirmar que também fica difícil para o indivíduo pesquisado mensurar seu grau de concordância, ou seja, se concorda parcialmente, esta 
concordância equivale a quanto? Muito? Pouco? Mais ou menos? A concordância parcial indica apenas uma tendência maior para essa direção.

Outra desvantagem é que na escala de 0 a 4 não existe uma categoria central e isso pode induzir os respondentes a uma determinada tendência. Incluir a opção "não sei” é uma sugestão para evitar esse problema na construção da escala. Nesse caso, Garland (1991) e Alexandre et al. (2003) advertem que esta opção pode reforçar uma tendência e compelir os respondentes a marcarem a direção à qual os pesquisadores estão "inclinados" a considerar socialmente mais adequada. Neste caso, a inexistência de uma categoria neutra impede os respondentes de informar que desconhecem o tema (não sei) ou que não têm opinião formada (indiferente).

$\mathrm{Na}$ escala de 0 a 5 , o problema pode aparecer com a categoria do meio, representando uma indecisão. Garland (1991) fez um estudo para comparar a escala Likert de 4 e 5 pontos para analisar a viabilidade da categoria do meio na escala de 5 pontos como demonstra a tabela 2, a fim de testar a pesquisa realizada por Worcester e Burns (1970 apud GARLAND, 1991). Como se pode observar na Tabela 2.

\section{Tabela 2 - Comparação das duas formas da escala sobre a importância da rotulagem dos produtos}

\begin{tabular}{lccr}
\hline \multicolumn{1}{c}{ Categorias } & Escala de 5 pontos $\%$ & Escala de 4 pontos \% & Diferença $4-5 \%$ \\
\hline Muito importante & 28 & 33 & 5 \\
Importante & 41 & 38 & -3 \\
Nem importante/ nem sem importância & 14 & NA* & NA* $^{*}$ \\
Sem importância & 8 & 16 & $8^{* *}$ \\
Nada importante & 8 & 18 & $10^{* *}$ \\
Não sei recuso a responder & 1 & 3 & 2 \\
Total & 225 & 223 & \\
\hline
\end{tabular}

(*) não aplicado - (**) estatisticamente significativo a 0,05 .

Fonte: Adaptado de Garland (1991).

O resultado do estudo de Garland (1991) apresentou consistência com o encontrado por Worcester e Burns (1970 apud GARLAND, 1991) ou seja, que os inquiridos tendem a dar uma resposta às perguntas, a fim de ser útil ou para agradar o entrevistador ou adivinhar o que pode ser a resposta socialmente aceitável. Mas, enquanto Worcester e Burns (1970 apud GARLAND, 1991) constataram que os entrevistados manifestam uma tendência para o lado positivo da escala, quando o ponto médio da escala é omitido, o estudo de Garland (1991) constatou o oposto. Isto sugere 
que a maneira pela qual as pessoas vão reagir a uma escala do tipo Likert sem um ponto médio depende do conteúdo específico (GARLAND, 1991).

De todo modo, percebe-se que a existência do ponto médio não obriga o entrevistado a assumir uma posição em relação ao objeto da pesquisa; ao contrário, a escala de quatro pontos induz a uma resposta positiva ou negativa, mesmo que desconheça o assunto ou não tenha posição tomada (Tabela 2). A escolha positiva ou negativa pode expressar como afirma Garland (1991), a resposta socialmente aceitável.

Assim, as conclusões de Garland apontam para a evidência de que a presença ou ausência de um ponto médio em uma escala de importância altera os resultados obtidos, ou seja, o problema ainda continua por resolver (GARLAND, 1991).

Portanto, considerando os estudos aqui apresentados sobre o uso da escala Likert, a sua aplicabilidade na educação será sempre duvidosa, desse modo, prejudicando a tomada de decisão no âmbito das políticas educacionais. Esse é o ponto que se pretende demonstrar no estudo da aplicação dessa escala na pesquisa TALIS (OCDE 2009).

\section{A Pesquisa TALIS (OCDE 2009)}

Para determinar se as políticas aplicadas estão gerando resultados satisfatórios, tem sido criados programas de pesquisas para evidenciar seus resultados. Os resultados TALIS (OCDE 2009) pretendem oferecer informações sobre o desempenho dos sistemas educacionais, e permitir comparação das condições do ensino e da aprendizagem, sob o ponto de vista dos professores e diretores de escola. A comparação realizada por organismos internacionais pode, segundo Ferrer (2002), além de oferecer um banco de dados com informações úteis, apresentar uma finalidade normativa, estabelecendo normas e critérios para definir padrões que se devem seguir e que podem servir de referência para avaliação.

O inquérito TALIS surgiu em 2005, da revisão da OECD sobre as políticas dos professores, quando identificou lacunas importantes nos dados internacionais e tem como objetivo ajudar os países a revisar e desenvolver políticas para tornar a profissão de professor mais atrativa e efetiva (OCDE 2009).

Neste sentido, é importante destacar que "[...] um dos objetivos mais importantes da OCDE é a busca e a promoção de certos valores, regras e políticas universais, tanto 
entre os Estados-membros como entre os não membros" (BEECH, 2012, p.419), o que explica o seu investimento nas pesquisas que desenvolve no âmbito da educação.

TALIS é, na verdade, um programa de pesquisas, desenvolvido em "rodadas" para levantar problemas escolhidos por cada um dos países envolvidos. Por decisão dos países participantes, o foco da primeira rodada da TALIS, referiu-se aos professores e diretores da educação secundária básica (nível 2 ISCED $^{3}$ 1997). A pesquisa examinou vários aspectos do desenvolvimento profissional do professor, as suas crenças, suas atitudes e práticas, bem como o feedback do professor e das lideranças escolares, em 23 países participantes ${ }^{4}$. A população-alvo é constituída de professores e diretores do ensino secundário básico, de escolas públicas e privadas dos países participantes. O tamanho mínimo da amostra foi definido em 200 escolas por país e 20 professores em cada escola. Foram realizados estudos para alcançar validade cultural e linguística dos instrumentos de pesquisa, aplicados tanto para as traduções quanto para as amostras de dados coletados. Não participaram da população-alvo, os professores das classes de alunos com necessidades especiais; substitutos, professores ocasionais ou de emergência, professores de turmas para adultos, professores em licença de longo prazo e professores que também eram diretores de suas escolas (OCDE 2009).

As datas de realização da coleta de dados foram outubro e novembro de 2007, para os países do hemisfério sul; e março a maio de 2008, para os países do hemisfério norte, tendo em vista as diferenças de calendário escolar. Os respondentes tiveram 45 minutos para completar os questionários, que foram preenchidos em papel ou online (OCDE, 2009).

Somente foram considerados para o estudo, os países que obtiveram respostas de $75 \%$ das escolas da amostra e as escolas com $50 \%$ dos professores dos questionários

\footnotetext{
${ }^{3}$ ISCED - International Standard Classification of Education: Classificação Internacional de Educação de 1997. É um instrumento internacional para identificar a equivalência ou similaridade dos níveis de educação entre os países. Estabelece seis níveis de educação: Educação pré-primária (ISCED nível 0); Educação primária (ISCED nível 1); Educação secundária (básica) (ISCED nível 2); Educação secundária (superior) (ISCED nível 3); Educação pós-secundária de nível não terciário (ISCED nível 4); e a Educação de nível 5, que representa a educação terciária e está dividido entre os níveis 5A e 5B. O nível 5A refere-se à graduação, Bacharelado ou Licenciatura; o nível 5B, geralmente, refere-se a programas mais curtos; e o nível 6 representa educação de nível terciário com pesquisa avançada, como por exemplo, doutorado ou PhD (OCDE 2009).

${ }^{4}$ Países participantes da TALIS: Países membros da OCDE - Austrália, Áustria, Bélgica (Comunidade Flamenga), Dinamarca. Hungria, Islândia, Irlanda, Itália, Coréia, México, Noruega, Polônia, Portugal, República Eslovaca, Espanha, Turquia. E os Países convidados - Brasil, Bulgária, Estônia, Lituânia, Malásia e Eslovênia. Ao todo, são 24 países participantes da primeira rodada do TALIS. Entretanto, uma vez que a Holanda não atendeu aos padrões das amostras, seus índices não foram incluídos nas tabelas internacionais, bem como nas análises. . Um resumo dos resultados conquistados pela Holanda pode ser encontrado no anexo do relatório TALIS (OCDE 2009).
} 
respondidos pelos professores, com o intuito de atingir $75 \%$ da resposta de todos os professores da amostra de cada país. Por não atender aos padrões estabelecidos, não foram considerados os dados da Holanda para efeitos de análise geral.

Deve ser levado em conta que os resultados fornecidos pela pesquisa, foram baseados nas respostas pessoais de professores e diretores e, portanto, representam suas opiniões, percepções, crenças e o relato de suas atividades. Ou seja, apresenta dados sobre como os professores percebem os ambientes de aprendizagem nos quais trabalham, o que os motiva e como as políticas e as práticas que são propostas são desenvolvidas na escola e na sala de aula. Assim, como qualquer dado pessoal, muitas das informações coletadas têm caráter subjetivo, diferindo da objetividade de dados mensuráveis, tais como, idade, tempo de experiência, número de alunos por sala de aula, etc. O mesmo pode ser dito em relação aos relatórios oferecidos pelos diretores sobre as características de suas escolas, os quais podem ser diferentes daqueles fornecidos pelos dados administrativos (OCDE 2009).

A escala Likert foi utilizada na pesquisa para aferir a opinião dos professores sobre diversos temas, a partir dos quais foram definidas as questões que apresentaram, na maioria, a opção pela escala de quatro pontos que, conforme os fundamentos descritos, apresenta problemas tanto em relação à formulação das questões quanto na intepretação das mesmas pelos respondentes.

\section{A utilização da escala Likert na pesquisa TALIS}

Para efeito do presente estudo, foram selecionados temas do questionário dos professores, nos quais é utilizada a escala Likert de 4 pontos, para avaliar níveis de concordância e discordância, isto é, foram oferecidas quatro opções para responder "até que ponto você concorda ou discorda das afirmações a seguir", salientando que poderia ser marcada apenas uma alternativa em cada linha entre as opções: discordo totalmente, discordo, concordo, concordo totalmente (OCDE, 2009).

A escala de 4 pontos foi utilizada para investigar três temas: avaliação e feedback, com duas questões; práticas de ensino, crenças e atitudes, com duas questões; e turma específica, com uma questão (Quadro 1).

\section{Quadro 1 - Escala Likert de 4 pontos na pesquisa TALIS: níveis de concordância e discordância}




\begin{tabular}{|c|c|}
\hline \multirow{2}{*}{ Tema } & Pergunta do questionário do professor \\
\hline \multirow{2}{*}{$\begin{array}{c}\text { Avaliação e } \\
\text { feedback }\end{array}$} & $\begin{array}{c}\text { Com relação à avaliação ou ao feedback (retorno) que você recebeu } \\
\text { nesta escola, até que ponto você concorda ou discorda das afirmações a seguir? }\end{array}$ \\
\cline { 2 - 3 } & $\begin{array}{c}\text { Gostaríamos agora de perguntar-lhe sobre o feedback (retorno) e/ou } \\
\text { avaliação de professores nesta escola de forma mais geral. Até que ponto você } \\
\text { concorda ou discorda com as afirmações a seguir? }\end{array}$ \\
\hline \multirow{2}{*}{$\begin{array}{c}\text { Práticas de ensino, } \\
\text { crenças e atitudes }\end{array}$} & $\begin{array}{l}\text { Gostaríamos de perguntar-lhe sobre suas crenças pessoais acerca do } \\
\text { ensino e da aprendizagem. Por favor, indique o quanto você discorda ou }\end{array}$ \\
\cline { 2 - 3 } & O quanto você concorda ou discorda com as seguintes afirmações .... \\
& $\ldots$ sobre você como professor nesta escola? \\
\hline \multirow{2}{*}{ Turma específica } & O quanto o que acontece nesta escola? \\
\hline
\end{tabular}

Fonte: OCDE (2009).

Para este estudo, foram selecionadas três questões: a questão $\mathrm{n}^{\circ} 31$ sobre a autoeficácia dos professores e a questão $\mathrm{n}^{\circ} 29$ sobre as crenças dos professores acerca das práticas de ensino e aprendizagem, do tema sobre práticas de ensino, crenças e atitudes; e a questão n ${ }^{\circ} 43$ sobre a turma específica, tendo em vista a sua relevância para a avaliação das condições de trabalho dos docentes, Para análise, foram selecionadas, a título de exemplo, algumas afirmações, considerando os limites de espaço do presente texto.

A investigação sobre a auto eficácia (LANDINI, 2013; LANDINI; TROJAN, 2014) do professor é justificada no relatório porque,

Professores com alta autoeficácia, esperam ter sucesso na área do ensino e de lidar bem com os estudantes. Isso influencia suas interpretações de sucesso e desapontamento, os padrões que eles colocam para si e suas abordagens para lidar com situações complicadas (BANDURA, 1997; ROSS, 1998). (OCDE, 2009).

A questão $n^{\circ} 31$ envolve seis afirmações para avaliar o nível de concordância dos professores sobre: sua satisfação com o trabalho; a sua influência na vida educacional dos alunos; a sua capacidade de motivar os alunos mais difíceis; o sucesso obtido com os alunos; a conquista da confiança dos alunos; o respeito recebido da comunidade. Foi selecionada para este estudo a afirmação sobre o progresso do professor com os alunos. 
Tabela 3 - Questão 31: Auto eficácia: progresso com os alunos (2007-08) (\% de professores do ensino secundário básico, que relataram os seguintes resultados).

\begin{tabular}{lllllllll}
\hline \multirow{2}{*}{ Países } & \multicolumn{3}{l}{$\begin{array}{l}\text { Se realmente me esforçar, posso conseguir que até meus alunos mais difíceis e } \\
\text { desmotivados façam progresso. }\end{array}$} \\
\cline { 2 - 9 } & \multicolumn{2}{l}{ Discordo Totalmente } & \multicolumn{2}{c}{ Discordo } & \multicolumn{2}{c}{ Concordo } & \multicolumn{3}{l}{$\begin{array}{l}\text { Concordo } \\
\text { Totalmente }\end{array}$} \\
\cline { 2 - 9 } & $\%$ & $(\mathrm{SE})$ & & $(\mathrm{SE})$ & & $(\mathrm{SE})$ & $\%$ & $(\mathrm{SE})$ \\
\hline Brasil & 1,2 & $(0,22)$ & 3,7 & $(0,90)$ & 9,4 & $(0,98)$ & 25,7 & $(1,07)$ \\
México & 0,4 & $(0,13)$ &, 0 & $(0,60)$ & 3,2 & $(1,01)$ & 42,3 & $(1,21)$ \\
Espanha & 2,5 & $(0,29)$ & 1,0 & $(1,07)$ & 4,2 & $(1,09)$ & 12,2 & $(0,67)$ \\
\multirow{2}{*}{ TALIS Média } & 1,3 & $(0,02)$ & 8,9 & $(0,11)$ & 6,5 & $(0,13)$ & 23,4 & $(0,10)$ \\
\hline
\end{tabular}

Fonte: OCDE (2009), Banco de Dados TALIS, 2009

Nesta afirmação (Tabela 3), quando perguntados se, mediante esforço pessoal, os professores podem conseguir que até seus alunos mais difíceis façam progresso, a maioria concordou. Isto significa que esta mesma maioria assume que é sua a responsabilidade pelo progresso dos alunos, esquecendo ou minimizando condições importantes que independem de sua vontade, como a condição socioeconômica e cultural dos alunos e a garantia das condições materiais adequadas, que são de responsabilidade do Estado ou da instituição mantenedora. Causa espanto que os professores concordem que o avanço dos seus alunos depende apenas do seu próprio esforço, ou seja, de sua autoeficácia [sic]. Seria conveniente investigar se as respostas dos professores são condicionadas pelas teorias relacionadas ao construtivismo, às competências e à autoeficácia ou pela formulação da questão e das opções oferecidas.

Cabem aqui as considerações de Poynter (2010) ao dizer que a escala Likert permite determinar a direção - positiva, neste caso - do respondente em relação à afirmação, mas, como adverte Garland (1991), a escala de 4 pontos pode estar reforçando uma tendência e compelindo os respondentes a marcarem a direção mais adequada ou socialmente mais desejável.

Na afirmação seguinte, sobre a percepção do sucesso dos professores em relação aos seus alunos, encontramos a mesma situação de predominância das respostas positivas, ou seja, de concordância em relação à afirmação e, neste caso, os percentuais são ainda mais elevados. Se observarmos a tabela 4, verificamos que os docentes os espanhóis $(80,3 \%$ e 9,1\%) são os que apresentam maior percentual de concordância, enquanto os brasileiros ( $73,2 \%$ concordam e $18,1 \%$ concordam totalmente) e os 
mexicanos $(72,1 \%$ concordam e $21,9 \%$, concordam totalmente) se aproximam mais da média TALIS $(76,1 \%$ e $16,2 \%)$.

Tabela 4 - Questão 31: Autoeficácia: Sucesso com os alunos (2007-08)

(Percentual de professores do ensino secundário básico, que relataram os seguintes resultados).

\begin{tabular}{lllllllll}
\hline & \multicolumn{4}{c}{ Professores relataram que são bem sucedidos com seus alunos } \\
\cline { 2 - 9 } Países & \multicolumn{2}{c}{ Discordo Totalmente } & \multicolumn{2}{c}{ Discordo } & & Concordo & \multicolumn{2}{c}{$\begin{array}{c}\text { Concordo } \\
\text { Totalmente }\end{array}$} \\
\cline { 2 - 9 } & $\%$ & $(\mathrm{SE})$ & & $(\mathrm{SE})$ & $\%$ & $(\mathrm{SE})$ & $\%$ & $(\mathrm{SE})$ \\
\hline Brasil & 0,3 & $(0,10)$ &, 4 & $(0,61)$ & 73,2 & $(0,98)$ & 18,1 & $(1,00)$ \\
México & 0,2 & $(0,07)$ &, 8 & $(0,55)$ & 72,1 & $(1,01)$ & 21,9 & $(0,98)$ \\
\multirow{2}{*}{ Espanha } & 0,4 & $(0,10)$ & 0,3 & $(0,61)$ & 80,3 & $(0,78)$ & 9,1 & $(0,61)$ \\
\multirow{2}{*}{ TALIS Média } & 0,2 & $(0,01)$ &, 5 & $(0,06)$ & 76,1 & $(0,09)$ & 16,2 & $(0,08)$ \\
\hline
\end{tabular}

Fonte: OCDE (2009), Banco de Dados TALIS.

Contudo, mais que analisar os resultados, cabe inquirir o que pode significar para os professores ser bem sucedido com os alunos da sua turma. O professor respondeu que conseguiu êxito no processo de ensino e aprendizagem ou que possui popularidade com os alunos? Além do mais, até que ponto um professor admitiria não ser bem sucedido, qualquer que seja a interpretação de sucesso? Se considerarmos a opção referente ao êxito na docência, seria conveniente verificar o desempenho escolar dos estudantes. De todo modo, não seria uma avaliação adequada se não forem ponderadas as condições socioeconômicas dos estudantes e os recursos materiais e pedagógicos disponíveis para a realização do processo educativo.

Em outra afirmação, sobre o quanto os professores estão fazendo diferença na vida educacional dos alunos (Tabela 5), a análise feita no relatório apresenta que a maioria (mais de 90\%) acredita que faz diferença (OCDE, 2009). Mas, para chegar a essa conclusão, foram somadas duas respostas (concordo 64,1\% e concordo totalmente $26,4 \%$ na média TALIS). Há de se pensar que apenas $26,4 \%$ concordam plenamente. Para evitar que sejam prejudicadas as comparações entre os países e a avaliação de políticas educacionais, que utilizem os dados da pesquisa, seria prudente replicar estas questões, incluindo uma alternativa neutra para avaliar a força dos resultados obtidos.

Tabela 5 - Questão 31: Auto eficácia: fazendo a diferença significativa educacional dos alunos (2007-08) 
(Percentual de professores do ensino secundário básico, que relataram os seguintes resultados).

\begin{tabular}{lllllllll}
\cline { 2 - 8 } Países & \multicolumn{2}{l}{ Discordo Totalmente } & \multicolumn{2}{l}{ Discordo } & \multicolumn{2}{c}{ Concordo } & \multicolumn{2}{c}{ Concordo Totalmente } \\
\cline { 2 - 9 } & $\%$ & $(\mathrm{SE})$ & & $(\mathrm{SE})$ & & $(\mathrm{SE})$ & & $(\mathrm{SE})$ \\
\hline Brasil & 0,8 & $(0,18)$ &, 8 & $(0,67)$ & 1,1 & $(1,08)$ & 0,3 & $(1,11)$ \\
México & 0,3 & $(0,15)$ &, 5 & $(0,38)$ & 1,2 & $(1,16)$ & 6,0 & $(1,25)$ \\
Espanha & 0,5 & $(0,12)$ & 0,4 & $(0,55)$ & 5,6 & $(0,81)$ & 3,5 & $(0,71)$ \\
\multirow{2}{*}{ TALIS média } & 0,5 & $(0,02)$ &, 9 & $(0,06)$ & 4,1 & $(0,11)$ & 6,4 & $(0,10)$ \\
\hline
\end{tabular}

Professores relataram fazer diferença significativa na vida de seus alunos

Fonte: OCDE (2009), Banco de Dados TALIS.

Outro ponto a considerar é que as afirmativas colocadas para avaliar as práticas de ensino, crenças e atitudes dos professores desconsideram os aspectos relacionados às políticas de financiamento da educação e de formação docente e à organização e gestão dos sistemas de ensino. Ao que parece, a intenção é atribuir somente ao professor a responsabilidade sobre os resultados do processo de ensino e aprendizagem. Segundo Freitas, o atual contexto, apresentado pelo autor como neotecnicista, considerando sua implicação com o campo econômico, é:

[...] apresentado agora sob a forma da teoria da "responsabilização" e/ou "meritocracia", [...] se propõe a mesma racionalidade técnica de antes na forma de "standards" de aprendizagem medidos em testes padronizados, com ênfase nos processos de gerenciamento da força de trabalho da escola (controle pelo processo, bônus e punições), ancoradas nas mesmas concepções oriundas da psicologia behaviorista, da econometria, das ciências da informação e de sistemas, elevadas à condição de pilares da educação contemporânea. (FREITAS, 2011, p.2).

No que se refere ao ensino para uma turma específica, questão $\mathrm{n}^{\circ} 43$, são apresentadas quatro afirmações para avaliar a concordância ou discordância do professor em relação aos problemas que podem prejudicar o processo de ensino e aprendizagem, utilizando a escala de quatro pontos, com as mesmas opções das anteriores.

Tabela 6 - Questão 43 Clima disciplinar em sala de aula: barulho em sala de aula (2007-08). 
(Percentual de professores do ensino secundário básico, que relataram os seguintes resultados).

\section{Há muito barulho na sala de aula}

\begin{tabular}{|c|c|c|c|c|c|c|c|c|}
\hline \multirow{3}{*}{ Países } & \\
\hline & \multicolumn{2}{|c|}{ Discordo Totalmente } & \multicolumn{2}{|c|}{ Discordo } & \multicolumn{2}{|c|}{ Concordo } & \multicolumn{2}{|c|}{ Concordo Totalmente } \\
\hline & $\%$ & (SE) & $\%$ & $(\mathrm{SE})$ & $\%$ & $(\mathrm{SE})$ & $\%$ & $(\mathrm{SE})$ \\
\hline Brasil & 8,9 & $(0,66)$ & 52,2 & $(1,29)$ & 32,0 & $(1,08)$ & 6,8 & $(0,48)$ \\
\hline México & 26,9 & $(1,17)$ & 55,8 & $(1,13)$ & 14,0 & $(0,90)$ & 3,3 & $(0,35)$ \\
\hline Espanha & 15,0 & $(0,84)$ & 46,6 & $(1,05)$ & 27,6 & $(1,01)$ & 10,8 & $(0,60)$ \\
\hline TALIS Média & 25,2 & $(0,11)$ & 48,4 & $(0,12)$ & 21,0 & $(0,11)$ & 5,4 & $(0,05)$ \\
\hline
\end{tabular}

Fonte: OECD (2009), Banco de Dados TALIS.

Nesse caso, pergunta o quanto o professor discorda ou concorda com as seguintes afirmações: a) No início da aula, tenho que esperar muito tempo até que os alunos se acalmem; b) Os alunos dessa turma ajudam a criar uma atmosfera agradável para o aprendizado; c) Eu perco muito tempo porque os alunos interrompem a aula; e, d) Há muito barulho nessa sala de aula (OCDE, 2009). Tomando como exemplo a última afirmação, verifica-se que a maioria dos professores investigados discorda ou discorda totalmente que "Há muito barulho em sala de aula", como se pode observar na tabela 6.

Ao analisar os resultados das opções discordo totalmente e discordo, observa-se que, nos três países selecionados - Brasil (8,9 e 52,2\%), México (26,9 e 55,8\%) e Espanha (15 e 46,6\%), respectivamente -, a grande maioria discorda que ocorra muito barulho em sua sala de aula, resultado semelhante à média TALIS (25,2 e 48,4\%). Entretanto, se confrontarmos essa questão, com a análoga do questionário do diretor (tabela 7), encontram-se resultados totalmente opostos. Ou seja, a maioria dos diretores afirma que o ensino está sendo prejudicado por perturbação em sala de aula.

Tabela 7 - Questão 30: Em que medida o ensino está sendo prejudicado pelos seguintes comportamentos

\begin{tabular}{ccc}
\hline & \multicolumn{2}{c}{ Perturbação em sala de aula } \\
\cline { 2 - 3 } Países & Média Percentual & Erro Padrão \\
\hline México & 72,00 & 3,60 \\
Espanha & 70,00 & 4,00 \\
Brasil & 60,00 & 3,00 \\
Média TALIS & 60,20 & 0,80 \\
\hline
\end{tabular}




\section{Fonte: OCDE (2009), Banco de Dados TALIS.}

Para esta questão também foi utilizada a escala de quatro pontos, porém as diferentes opções - de forma alguma; muito pouco; até certo ponto; muito - permitem estabelecer, gradativamente, a medida do barulho. Vale ressaltar que, essa mesma questão está presente no questionário da escola, aplicado pelo Programa Internacional de Avaliação de Estudantes (PISA) em 2009 (OCDE, 2010). Assim, pergunta-se: Por que não foram apresentadas as mesmas opções para os professores?

As opções oferecidas ao professor não apresentam a mesma possibilidade de medida, porque não há como estabelecer qual é a intensidade das opções concordo e discordo. Se concordo totalmente e discordo totalmente correspondem a $100 \%$ de peso, qual é o grau que se pode estabelecer para as duas outras opções? Assim sendo, concordo significa menos de 100\% de concordância. Mas, quanto? E, ao contrário, qual é o percentual que se pode atribuir à opção discordo? Se as opções concordo e discordo corresponderem a 50\%, elas se anulam, significam a mesma coisa. Nesse caso, quando se somam os resultados de concordo totalmente e concordo ou discordo totalmente e discordo ignora-se a diferença de intensidade entre as escalas. Esta conclusão também corrobora com as conclusões dos estudos de Garland (1991).

Conforme observado, no relatório TALIS (OCDE, 2009), as tabelas, referentes aos fatores relacionados aos alunos que prejudicam o ensino, apresentam os resultados somados em dois grupos, discordo totalmente e discordo como uma única alternativa e o mesmo para as opções concordo e concordo totalmente. Assim, porque utilizar a Escala Likert de quatro pontos se a Escala de Thurstone (OLIVEIRA, 2001) propõe exatamente a escolha entre duas alternativas - concordo e discordo? Qual é a intenção? Se a proposição de quatro ou mais opções pressupõe uma diferença significativa de intensidade entre as alternativas, estatisticamente, não se podem apresentar somatórias resultantes da junção de respostas, pois, cada uma representa um grau de valor.

Retomando o problema da perturbação em sala de aula, no caso do questionário do diretor, o relatório também apresenta os resultados somados, apesar das opções indicarem um grau de intensidade distinto e objetivo (Tabela 7), além de não permitir identificar quais foram as opções somadas para afirmar que, na maioria dos países pesquisados, os distúrbios em sala prejudicam o ensino (OCDE, 2009).

Outra consideração importante é a contradição apresentada pelas respostas dos professores e dos diretores. Enquanto a maioria dos diretores afirma esse problema - 
Brasil (60,2\%), Espanha (70,5\%), México (71,9\%) e Média TALIS (60,2\%) -, a maioria dos professores discorda que há muito barulho em sala de aula - Brasil (8,9 e 52,2\%), México (26,9 e 55,8\%), Espanha (15 e 46,6\%) e média TALIS (25,2 e 48,4\%), respectivamente em relação a discordo totalmente e discordo. É possível que a diferença esteja relacionada com a forma de apresentação da questão e das opções de escolha. Outra possibilidade é colocar em dúvida o entendimento da pergunta pelo professor ou o grau de subjetividade que esta encerra.

Assim, se observarmos outras afirmações referentes à mesma questão verifica-se que há resultado similar de discordância em relação às afirmações "No início da aula, tenho que esperar muito tempo até que os alunos se acalmem" e "Eu perco muito tempo porque os alunos interrompem a aula" se comparado à questão do barulho. Também não se deve desconsiderar a interpretação do professor sobre o conceito de "muito barulho".

\section{Tabela 8 - Comparação entre variáveis da questão no 30 - Questionário do professor}

\begin{tabular}{lcccccc}
\hline \multirow{2}{*}{ Países } & \multicolumn{2}{c}{ Muito barulho em sala } & \multicolumn{2}{c}{$\begin{array}{c}\text { Aguardando alunos se } \\
\text { acalmarem }\end{array}$} & \multicolumn{2}{c}{ Interrupções em sala } \\
\cline { 2 - 7 } & $\begin{array}{l}\text { Discordo } \\
\text { totalmente }\end{array}$ & Discordo & $\begin{array}{l}\text { Discordo } \\
\text { totalmente }\end{array}$ & Discordo & $\begin{array}{l}\text { Discordo } \\
\text { totalmente }\end{array}$ & Discordo \\
\hline Brasil & 8,9 & 52,2 & 11,3 & 47,2 & 8,9 & 56,6 \\
México & 26,9 & 55,8 & 36,8 & 47,6 & 23,5 & 59,0 \\
Espanha & 15,0 & 46,6 & 15,7 & 43,0 & 12,1 & 44,9 \\
TALIS Média & 25,2 & 48,4 & 21,5 & 42,4 & 17,0 & 52,9 \\
\hline
\end{tabular}

Fonte: OECD (2009), TALIS.

$\mathrm{Na}$ questão 29, referente às crenças dos professores acerca do ensino e da aprendizagem, também é utilizada a Escala Likert de 4 pontos, com as mesmas opções de concordância. Os dois índices utilizados para medir as crenças dos professores sobre as práticas de ensino e aprendizagem são classificados como prática construtivista e prática de transmissão direta, que englobam os itens do questionário enumerados no Quadro 2.

\section{Quadro 2 - Crenças dos professores sobre ensino e aprendizagem}

\section{Práticas de Transmissão Direta}

- Professores bons e eficazes demonstram a forma correta de se resolver um problema.

- Instrução deve ser construída em torno de problemas com respostas claras e corretas e em torno de ideias que a maioria dos estudantes pode compreender rapidamente. 
- O quanto os estudantes aprendem depende de quanto conhecimento prévio eles possuem.

- Uma sala de aula quieta geralmente é necessária para o ensino e aprendizagem eficazes.

\section{Práticas Construtivistas}

- Meu papel como professore é facilitar a indagação do estudante.

- Os alunos aprendem mais ao solucionar os problemas por eles mesmos.

- Os alunos devem poder pensar nas soluções para problemas práticos sozinhos, antes de o professor demonstrar como o mesmo é resolvido.

- O processo de raciocínio e investigação é mais importante do que um conteúdo específico.

Fonte: Questionário TALIS (OCDE, 2009).

$\mathrm{O}$ princípio teórico adotado na pesquisa para examinar as crenças, atitudes e práticas dos professores fundamenta-se no construtivismo, como se pode verificar no relatório, quando apresenta dois argumentos a favor desta teoria. Primeiro, afirma que é um bom sinal o desenvolvimento profissional ser positivamente associado com crenças construtivistas e negativamente com crenças de transmissão direta; e, segundo, porque as práticas construtivistas estão associadas com práticas de instrução mais variadas (OCDE, 2009).

No relatório a perspectiva construtivista está descrita como aquela que "[...] foca no estudante como um participante ativo no processo de aquisição do conhecimento [...]; [dá] aos estudantes a chance de desenvolver soluções aos problemas [...] e [permite] que os alunos tenham um papel ativo nas atividades." (OCDE, 2009, p.92). Em contraste, a perspectiva da transmissão direta do ensino e aprendizagem do estudante, sugere que o papel do professor é " [...] comunicar o conhecimento de modo claro e estruturado [...]; fornecer aos estudantes problemas claros e 'resolvíveis'; [...] e garantir a calma e a concentração na sala de aula" (OCDE, 2009, p.93). A partir dessa explicação, pode-se concluir que a denominada prática de transmissão direta é aquela que conhecemos como tradicional - pautada na transmissão de conhecimentos e na centralidade da ação do professor - e, por outro lado, a construtivista - pautada na atividade e na experimentação, cuja centralidade está na ação do aluno (SAVIANI, 2005). Para analisar as perguntas elaboradas e os resultados apresentados pelo informe TALIS, deve-se levar em consideração esse ponto de vista (Gráfico 1).

\section{Gráfico 1 - Perfil dos países das crenças sobre as práticas de ensino} (2007-08) 


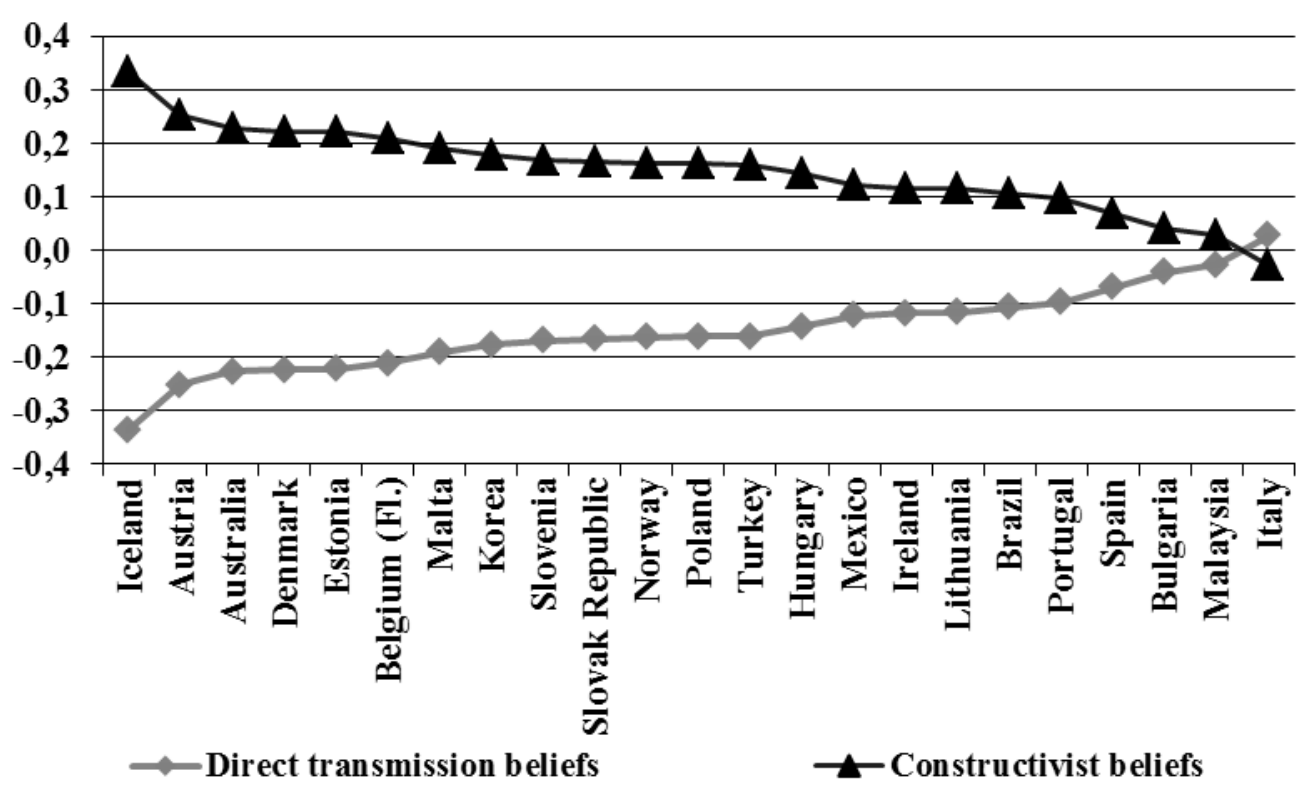

Fonte: OECD (2009), TALIS Database.

Neste sentido, pode-se alegar que, aparentemente, os indicadores foram elaborados para reforçar as práticas construtivistas como as mais adequadas. Assim, ao responder às questões citadas, o professor tende a concordar com as práticas que dão ao aluno "a chance de desenvolver soluções aos problemas" e não àquelas que enfatizam o papel do professor na apresentação das respostas certas. Somando-se a isso, a utilização da escala de 4 pontos reforça a possibilidade de levar os professores a concordar com as alternativas mais aceitas socialmente. Ou, neste caso, aquelas que estão mais em evidência no campo pedagógico, conforme destaca o relatório, afirmando que em todo o mundo, pesquisadores da educação e instrutores de professores promovem as visões construtivistas sobre a instrução (OCDE, 2009, p.120).

Com efeito, o gráfico 1 (que é apresentado no relatório) mostra que na maioria dos países, com exceção da Itália, há uma predominância em relação à prática construtivista. A partir das considerações citadas, pode-se inferir que há possibilidade de haver indução desta tendência. Assim sendo, reforça-se que o estudo de qualquer pesquisa que utilize métodos estatísticos de escala Likert deve analisar os objetivos, a opção teórica e a adequação dos métodos empregados para evitar resultados imprecisos.

\section{Considerações Finais}


Propôs-se, neste estudo, ponderar sobre as questões e as análises apresentadas no relatório TALIS (OCDE, 2009) para verificar as perspectivas do uso da Escala Likert em estudos desta natureza. Parte-se do princípio segundo o qual a escolha e o uso adequado de métodos estatísticos em pesquisas de larga escala pode ser útil para orientar políticas educacionais, caso contrário, pode conduzir a interpretações equivocadas ou duvidosas.

Se a vantagem da escala de Likert é a possibilidade de identificar a direção da atitude do respondente em relação a cada afirmação, sendo ela positiva ou negativa, a elaboração do conteúdo das opções para resposta, bem como, a escolha da escala adequada para medir o grau de intensidade da mesma tem efeito importante nos resultados e nas possibilidades de compreensão da realidade investigada.

No caso da pesquisa TALIS (OCDE, 2009), a escolha da escala de 4 pontos e das opções oferecidas prejudicou a aferição dos resultados e permitiu interpretações que podem não corresponder aos fatos. Esta escolha admite apenas a ordenação da atitude de concordância dos indivíduos com relação à determinada afirmação, mas não apresenta condições para dizer o quanto o indivíduo concorda ou discorda mais do que outro. E, no caso das opções, a concordância parcial indica apenas uma tendência maior para essa direção.

Segundo estudos de Garland (1991), a inexistência de uma categoria central pode induzir a uma determinada tendência e compelir os respondentes a marcar a opção considerada socialmente mais adequada, mesmo que desconheça o assunto ou não tenha posição tomada. Além disso, há evidências de que a presença ou ausência de um ponto médio em uma escala de importância altera os resultados obtidos. Portanto, os estudos aqui apresentados sobre o uso da escala Likert, indicam que a sua aplicabilidade na educação tende a ser imprecisa, prejudicando a tomada de decisão no âmbito das políticas educacionais.

$\mathrm{Na}$ pesquisa TALIS (OCDE, 2009), pode-se constatar que a maioria dos professores é levada a assumir toda a responsabilidade pelo progresso dos alunos, quando concorda que, mediante seu esforço pessoal, pode conseguir que até seus alunos mais difíceis façam progresso, confirmando a ênfase na concepção de autoeficácia e na prática construtivista de Bandura, que fundamenta a pesquisa, conforme citado no relatório TALIS (OCDE, 2009).

Também se encontrou contradição entre os questionários, quando se confrontou a questão sobre barulho em sala de aula, na qual a maioria dos professores investigados 
discorda ou discorda totalmente, com a análoga oferecida ao diretor, que apresenta resultados totalmente opostos. Ainda que tenha sido utilizada a escala de quatro pontos, as diferentes opções do diretor permitiram estabelecer a intensidade da medida, causando questionamento sobre a razão para não apresentar as mesmas para os professores.

Outro problema refere-se à soma dos resultados de concordo totalmente e concordo ou discordo totalmente e discordo, ignorando a diferença de intensidade entre as escalas. Neste caso, não se entende qual seria a intenção de utilizar a Escala Likert de quatro pontos se a Escala de Thurstone (OLIVEIRA, 2001) propõe exatamente a escolha entre duas alternativas, sem a pretensão de medir o grau de concordância. A proposição de quatro opções pressupõe uma diferença significativa de intensidade entre as alternativas e, estatisticamente, não se podem apresentar somatórias das respostas.

Outro ponto a considerar é que as afirmativas colocadas para avaliar as práticas de ensino, crenças e atitudes dos professores desconsideram os aspectos relacionados às políticas educacionais, isentando o Estado de sua responsabilidade na garantia de condições adequadas para o trabalho docente. Ao que parece, a intenção é atribuir somente ao professor a responsabilidade sobre os resultados do processo de ensino e aprendizagem.

Assim, a partir dos estudos realizados podem-se identificar algumas evidências de que o viés de desejabilidade social pode induzir a uma determinada resposta, como é o caso da questão que investiga a crença dos professores sobre as práticas construtivistas e de transmissão direta. Talvez, ainda mais, se os professores entenderem a pesquisa como um instrumento de avaliação do seu desempenho.

No caso da pesquisa avaliada, para evitar que sejam prejudicadas as comparações entre os países e a avaliação de políticas educacionais, que utilizem os dados da pesquisa, seria prudente revisar os questionários, a escala escolhida e opções oferecidas aos respondentes para avaliar a força dos resultados obtidos e evitar distorções dos resultados obtidos.

A partir das considerações citadas, pode-se inferir que há possibilidade de haver indução de determinada tendência. Assim, para realizar uma pesquisa utilizando métodos estatísticos de Escala Likert ou tomar seus resultados para comparar e avaliar políticas é fundamental analisar os objetivos, a opção teórica e a adequação dos métodos empregados. 


\section{COMPARATIVE STUDIES FROM THE APPLICATION OF THE FOUR- POINT LIKERT SCALE: A METHODOLOGICAL STUDY OF THE TALIS SURVEY (OECD, 2009)}

ABSTRACT: The authors discuss the use of the Likert Scale in the Teaching and Learning International Survey (TALIS), a theme justified by the recurrent use of statistics in educational research, especially those allowing international comparative studies. This paper aims at discussing the TALIS report (OECD, 2009), while seeing how one can use the Likert Scale in studies using the results of that research. For that, the authors applied the scale statistical fundamentals and technical procedures, as did Reis (1997), Garland (1991) and Oliveira (2001) and others, to examine two questions given to teachers who use the four-point Likert scale, having in mind what Alexandre et al. (2003) warn about this option being able of reinforcing a trend and compelling the respondents to mark the most suitable option. The results suggested problems in formulating the questions applied and in the analyses present in the report, which impair the evaluation of the topics investigated in the TALIS survey.

KEYWORDS: Educational policy. TALIS. Statistics.

\section{REFERÊNCIAS}

ALEXANDRE, J. W. C. et al. Análise do número de categorias da escala de Likert aplicada à gestão pela qualidade total através da teoria da resposta ao item. In: XXIII ENCONTRO NACIONAL DE ENGENHARIA DE PRODUÇÃO, 2003, Ouro Preto. Anais... Disponível em:

<http://www.abepro.org.br/biblioteca/ENEGEP2003_TR0201_0741>. Acesso em: 24 abr. 2014.

BEECH, J. Quem está passeando pelo jardim global? Agências internacionais e transferência educacional. In: UNESCO/OREALC. Educação na América Latina. Brasília: UNESCO/CAPES, 2012. p.396-416.

BRANDALISE, L. T. Modelos de medição de percepção e comportamento: uma revisão. Florianópolis: LGTI. Laboratório de Gestão Tecnologia e Informação. Universidade Federal de Santa Catarina, Brasil, 2005. Disponível em: <http://www.lgti.ufsc.br/brandalise.pdf>. Acesso em: 28 abr. 2014.

CHISNALL, P. Marketing research: analysis and measurement. New York: McGrawHill, 1973.

CRESPO, A. A. Estatística fácil. 18.ed. São Paulo: Saraiva, 2002.

FERRER J, F. La educación comparada actual. Barcelona: Ariel, 2002.

FREITAS, L. C. Responsabilização, meritocracia e privatização: conseguiremos escapar ao neotecnicismo? In: III SEMINÁRIO DE EDUCAÇÃO BRASILEIRA PROMOVIDO PELO CEDES NO SIMPÓSIO PNE: DIRETRIZES PARA AVALIAÇÃO E REGULAÇÃO DA EDUCAÇÃO NACIONAL, 2011, Campinas. 
Anais... Disponível em: <http://www.cedes.unicamp.br/seminario3/luiz_freitas.pdf >. Acesso em: 20 fev. 2014.

GARLAND, R. The mid-point on a rating scale: is it desirable? Marketing Bulletin, [S.1.], n.2, p.66-70, 1991. Disponível em: <http://marketing-

bulletin.massey.ac.nz/v2/mb_v2_n3_garland.pdf>. Acesso em: 15 jun. 2014.

LANDINI, S. R. Subjetivismo e Educação: analisando o inquérito TALIS (OCDE). Políticas públicas, Porto Alegre, v.6, n.2, p.131-144, 2013.

.; TROJAN, R. M. Presupuestos epistemológicos del informe TALIS: ¿qué espera la OCDE del profesorado? Profesorado. Revista de Currículum y Formación de Profesorado, Granado, v.18, n.2, p.321-333, may./ago. 2014.

LIMA, L. C. S. et al. A satisfação do manutentor na área industrial: o caso em uma indústria frigorífica. Revista Brasileira de Tecnologia Agroindustrial, Ponta Grossa, v.6, n.2, p.757-769, 2012. Disponível em:

<http://revistas.utfpr.edu.br/pg/index.php/rbta/article/view/901/860>. Acesso em: 25 abr. 2014.

MATTAR, F. N. Pesquisa de marketing. São Paulo: Altas, 1996.

Pesquisa de marketing. Edição Compacta. 3.ed. São Paulo: Atlas, 2001.

MORAIS, C. M. Escalas de medida, estatística descritiva e inferência estatística. Bragança: Escola Superior de Educação. Instituto Politécnico de Bragança, 2005. Disponível em: <https://bibliotecadigital.ipb.pt/bitstream/10198/7325/1/estdescr.pdf>. Acesso em: 12 mai. 2013.

OCDE. Organização de Cooperação e Desenvolvimento Econômico. TALIS: Teaching and Learning International Survey 16/06/2009 [online]. 2009. Disponível em:

<www.oecd.org/edu/talis>. Acesso em: 30 set. 2009.

School questionnaire for PISA 2009 [online]. Disponível em:

<https://pisa2009.acer.edu.au/downloads/PISA09_School_questionnaire.pdf>. Acesso: 15 out. 2014.

OCKERT, D. Substantive scale verification: a Likert scale analysis and critique of University Student Pedagogical activity preferences. JALT Hokkaido Journal, Hokkaido/Japão, v.9, p.48-64, 2005. Disponível em:

<http://jalthokkaido.org/jh_journal/2005/Ockert.pdf>. Acesso em: 15 ago. 2014.

OLIVEIRA, T. M. V. Escalas de mensuração de atitude: Thrstone, Osgood, Stapel, Likert, Guttman, Alpert. Revista Administração online, São Paulo, v.2, n.2, abr.jun. 2001. Disponível em: <http://www.fecap.br/adm_online/art22/tania.htm>. Acesso em: 16 mai. 2014.

POYNTER, R. The Likert scale - TARSK 14 (Things All Researchers Should Know) [online]. 2010. Disponível em: 
<http://thefutureplace.typepad.com/the_future_place/2010/09/the-likert-scale-tarsk-14things-all-researchers-should-know.html>. Acesso em: 29 jun. 2014.

REIS, E. Estatística multivariada aplicada. Lisboa: Edições Silabo, 1997.

Estatística Descritiva. 7.ed. Lisboa: Sílabo, 2008.

SAVIANI, D. As concepções pedagógicas na história da educação brasileira. Texto elaborado no âmbito do projeto de pesquisa "O espaço acadêmico da pedagogia no Brasil", financiado pelo CNPq, para o "Projeto 20 anos do Histedbr". Campinas: CNPq, 2005. Disponível em: <http://www.joinville.udesc.br/portal/professores/maria/materiais/3_Saviani_Conce pcoes_Pedagogicas.pdf >. Acesso em: 15 jan. 2014. 